\title{
Practices During Preparturition and Normal Delivery Care in a Maternity Hospital in Southern Brazil
}

\author{
Camila Rocha Schneckenberg ${ }^{1}$ \\ https://orcid.org/0000-0003-3148-678X
}

Ana Claudia Garabeli Cavalli Kluthcovsky ${ }^{1}$

https://orcid.org/0000-0002-4772-2970

\author{
Ana Paula Ditzel ${ }^{1}$ \\ https://orcid.org/0000-0002-0100-8333
}

1State University of Ponta Grossa, Ponta Grossa, Paraná, Brazil

Received: 2019.07.13; Accepted: 2020.02.18.

*Correspondence: camila.crs@hotmail.com (C. R. S.); anafabio2009@gmail.com (A.C.G.C.K.); prof.go.anapaula@gmail.com (A.P.D).

\section{HIGHLIGHTS}

- Evaluation of safe and unsafe practices in deliveries.

- Delivery care with minimum intervention is still a challenge

- Training health workers, safe delivery kits and effective referral system required.

- Skilled attendant's deliveries were safer with some failures in hygienic practices.

- $29 \%$ women experienced obstetric complication not received emergency obstetric care.

- Training health workers, safe delivery kits and effective referral system required.

- Promoting a normal birth

\begin{abstract}
This study aimed to evaluate the practices of hospital care during pré parturition and normal delivery in a maternity hospital in Southern Brazil. A cross-sectional and quantitative study performed with 82 postpartum women. Results were evaluated for the total number of postpartum women and in two groups according to hospital delivery time ( $\leq 8$ and $>8$ hours). Chi-square and Fisher Exact tests were used. with a significance level of $5 \%$. Percentages of useful practices were: oral diet $(23.2 \%)$, freedom of position and movement (90.2\%), non-pharmacological methods to alleviate pain (64.6\%), companion in prepartum $(62.1 \%)$ and parturition (42.5\%) and partogram (62.2\%). Harmful practices: enema (3.7\%), trichotomy (3.7\%), lithotomy position (92.7\%) and Kristeller maneuver (20.7\%). Practices used inappropriately: amniotomy (4.9\%), oxytocin (41.5\%), analgesia (1.2\%) and episiotomy (36.6\%). The hospital labor time above 8 hours was associated with offering oral diet $(p<0.001)$, use of non-pharmacological methods for pain relief $(p<$ $0.01)$, oxytocin infusion $(p=0.01)$ and episiotomy $(p<0.01)$. The delivery care with minimum intervention compatible with the recommendations is still a challenge.
\end{abstract}

Keywords: obstetric labor; natural childbirth; health services research. 


\section{INTRODUCTION}

Assistance in labor and birth in Brazil is in a transitional period, from a model in which labor is considered a medical and risk event, occurring in a hospital environment with unnecessary and harmful interventions to a progressive insertion of humanization principles with woman-centered care[1]. However, excessive labor and delivery medicalization is still a reality in Brazilian obstetric care [2-3].

The hegemonic biomedical model in obstetric and neonatal care, as well as the uncritical use of technical knowledge, can contribute to an increase in risks with a consequent worsening in maternal and infant morbimortality indicators [2]. Aiming to improve those indicators, the World Health Organization (WHO) proposed, in 1996, the adequate use of obstetrical technologies based on scientific evidence, which classifies obstetric actions in normal childbirth according to utility criteria, efficacy and absence of dangerousness [4], approved later by the Ministry of Health [5].

In this sense, health indicators can be a reflection of the availability and quality of care offered by health services to pregnant women, postpartum women and newborns [6-7]. The analysis of indicators and evaluations of obstetric practices are very important, since they can help managers and healthcare services professionals towards actions and resources according to actual needs [8]. In addition, the quality of obstetric and neonatal care will depend on integration of all to ensure compliance with constitutional principles of universality of access, equity and integral care.

Given this scenario, and due to the fact that there are few studies on the matter, this study aims to evaluate the practices in hospital care during labor and normal delivery in a maternity hospital in Southern Brazil.

\section{MATERIAL AND METHODS}

A cross-sectional quantitative study was carried out with a consecutive sample of normal postpartum postpartum women, referred to as a usual risk pregnancy for a maternity hospital linked to the Brazilian Unified Health System (SUS), in Southern Brazil. The sample size was calculated based on an estimate episiotomy rate of $50 \%$ [9], $25 \%$ relative precision and significance level of $5 \%$, resulting in a sample of at least 61 normal deliveries.

For the data collection, a consultation was first made to the admission system, searching all admitted patients as admission for delivery. Among all admitted pregnant women, those who had normal labor were selected. All postpartum women who had normal births classified as usual risk on the Pregnant Woman Card, who were 18 years old or older and who agreed to participate by signing the Informed Consent Form were included. Postpartum women submitted to cesarean section, those classified as moderate or high risk on the Pregnant Woman Card and who had stillbirth were excluded. Of the 162 births registered in the period between September and December 2016, 106 were normal deliveries and 59 were cesarean deliveries. Of the 106 normal deliveries, 24 (22.6\%) were excluded from the research: 17 postpartum women were less than 18 years old, three stillbirths, and one normal home birth. There were two losses and one refusal, totaling 82 postpartum women surveyed.

The data were obtained through interviews with the puerperae during the hospitalization period, up to 48 hours after delivery. Those interviews were performed with the parturient in the bed, in a standardized way by the same interviewer, in a single meeting. In addition to the interview with the postpartum women, data were collected from the Pregnant Woman Card and the medical record.

Data collection included socioeconomic, obstetric and newborn data. The socioeconomic data were: age, marital status, skin color, schooling, paid work and monthly per capita family income. The obstetric and newborn data were: number of prenatal consultations, number of pregnancies, intercurrences in pregnancy, gestational age, length of hospital stay until delivery in hours, newborn weight in grams and Apgar in the first and fifth minutes.

To evaluate the obstetric practices of care for normal birth, a classification organized in three categories was used: practices that were demonstrably useful and should be encouraged, practices that are clearly harmful or ineffective and should be eliminated and practices frequently used inappropriately during labor and delivery [1].

The different practices of attention to normal delivery were analyzed for the total number of puerperae and, for comparative purposes, in two groups according to the time of labor in hospital delivery. The hospital labor time was defined as the period between admission and the time of birth, categorizing the parturients with hospital labor time in up to 8 and greater than 8 hours. The 8 -hour hospital stay was chosen because 
the duration of active labor takes an average of five hours for multiparous women and eight hours for primiparous women [10].

Data were presented by absolute and relative frequencies and descriptive statistical measures. Comparisons were performed using Pearson's Chi-square test and Fisher's exact test, with a significance level of $5 \%$. The study was approved by the Research Ethics Committee of Universidade Estadual de Ponta Grossa under protocol number 1.652.509 and CAAE 57695516.0.0000.0105.

\section{RESULTS}

The postpartum women had a mean age of $23.3( \pm 5.6)$ years, and the other socioeconomic, obstetric and newborn data are presented in Table 1. For the total number of postpartum women, the vast majority $(89.0 \%)$ was 20 years old or older and had a stable partner (86.6\%). The majority self-declared as white $(63.4 \%)$ and had more than eight years of study (57.3\%). A little more than half reported not having a paid work $(54.9 \%)$ and the majority declared monthly per capita family income lower than one minimum wage (87.7\%).

Table 1 shows the distribution of the total number of puerperae according to socioeconomic, obstetric and newborn data.

With regard to gestation, all postpartum women in the study reported having undergone prenatal care $(100 \%)$, with almost $85 \%$ having seven or more prenatal consultations. Most of the women $(76.8 \%)$ were multiparous (two deliveries or more) and the hospital labor time was up to eight hours in $63.4 \%$ of the sample. Less than $20 \%$ of the women presented some type of intercurrence during pregnancy. At the time of admission, almost all the puerperae (96.3\%) had full term gestation (37 weeks of gestation or more) and the mean gestational age at admission was $39.0( \pm 1.4)$ weeks.

Low percentages of prematurity (3.7\%) and low birth weight $(2.6 \%)$ were observed. The majority $(91.0 \%)$ of newborns had adequate weight at birth, between 2,500 and 3,999 grams, being the mean birth weight of $3,254.3$ grams ( \pm 393.0$)$. Apgar values in the first and fifth minutes were equal to or greater than 8 in $86.3 \%$ and $98.7 \%$ of the newborns, respectively (Table 1 ).

Table 2 presents the occurrence of practices that were shown to be useful during labor and delivery for the total number of postpartum women and for those with hospital labor lasting up to eight hours and more than eight hours. The majority of postpartum women received an oral diet (76.8\%), had freedom of position and movement during labor $(90.2 \%)$, had some non-pharmacological method for pain relief such as massage and baths (64.6\%) and had their companion of choice during labor $(62.1 \%)$. However, only $41.5 \%$ of the puerperae reported the presence of a companion during the delivery. In most medical records, the partogram was present and completely filled, and in $37.8 \%$ they were incompletely filled or were not in the medical record. There was a significant association for postpartum women with hospital labor time of more than 8 hours and offering of oral diet $(p<0.001)$ and non-pharmacological methods for pain relief $(p<0.01)$ in relation to postpartum women with hospital labor time of up to 8 hours (Table 2). 
Table 1. Distribution of the total number of puerperae according to socioeconomic, obstetric and newborn data $(n=82)$.

\begin{tabular}{|c|c|c|}
\hline Variables & $\mathrm{n}$ & $\%$ \\
\hline \multicolumn{3}{|l|}{ Age in years } \\
\hline Less than 20 & 9 & 11.0 \\
\hline 20 or above & 73 & 89.0 \\
\hline \multicolumn{3}{|l|}{ Marital status } \\
\hline Without a partner & 11 & 13.4 \\
\hline With a partner & 71 & 86.6 \\
\hline \multicolumn{3}{|l|}{ Skin color } \\
\hline Non-white & 30 & 36.6 \\
\hline white & 52 & 63.4 \\
\hline \multicolumn{3}{|l|}{ Schooling } \\
\hline Up to 8 years of study & 35 & 42.7 \\
\hline Over 8 years of study & 47 & 57.3 \\
\hline \multicolumn{3}{|l|}{ Paid work } \\
\hline No & 45 & 54.9 \\
\hline Yes & 37 & 45.1 \\
\hline \multicolumn{3}{|c|}{ Monthly family income ${ }^{*}$ per capita in reais ${ }^{a}$} \\
\hline Up to 880.00 & 71 & 87.7 \\
\hline$>880.00$ & 10 & 12.3 \\
\hline \multicolumn{3}{|l|}{ Prenatal consultations } \\
\hline$\leq 6$ & 13 & 15.9 \\
\hline 7 or more & 69 & 84.1 \\
\hline \multicolumn{3}{|l|}{ First pregnancy } \\
\hline Yes & 19 & 23.2 \\
\hline No & 63 & 76.8 \\
\hline \multicolumn{3}{|l|}{ Time of hospital labor } \\
\hline$<8$ & 52 & 63.4 \\
\hline 8 or more & 30 & 36.6 \\
\hline \multicolumn{3}{|l|}{ Intercurrences in pregnancy } \\
\hline Yes & 14 & 17.1 \\
\hline No & 68 & 82.9 \\
\hline \multicolumn{3}{|l|}{ Gestational age } \\
\hline$<37$ weeks & 3 & 3.7 \\
\hline 37 weeks or more & 79 & 96.3 \\
\hline \multicolumn{3}{|l|}{ Birth weight in grams ${ }^{\mathrm{b}}$} \\
\hline$<2,500$ & 2 & 2.6 \\
\hline 2,500 to 3,999 & 71 & 91.0 \\
\hline 4,000 or more & 5 & 6.4 \\
\hline \multicolumn{3}{|l|}{ Apgar in the first minute } \\
\hline$\leq 7$ & 11 & 13.7 \\
\hline 8 or more & 69 & 86.3 \\
\hline \multicolumn{3}{|l|}{ Apgar in the fifth minute } \\
\hline$\leq 7$ & 1 & 1.3 \\
\hline 8 or more & 78 & 98.7 \\
\hline
\end{tabular}

${ }^{*}$ Amount of $\mathrm{R} \$ 880.00$ was equivalent to a minimum wage during the period of data collection. No information or the parturient could not inform: ${ }^{a} n=1(1.2 \%),{ }^{b} n=4(4.9 \%),{ }^{c} n=2(2.4 \%),{ }^{d} n=3$ $(3.6 \%)$. 
Table 2. Frequency of practices demonstrably useful during labor and delivery, for the total number of postpartum women and with up to 8 hours and more than 8 hours of hospital labor $(n=82)$

\begin{tabular}{|c|c|c|c|c|c|c|c|}
\hline \multirow{3}{*}{ Variables } & \multirow{2}{*}{\multicolumn{2}{|c|}{ Total }} & \multicolumn{4}{|c|}{$\begin{array}{c}\text { Time of hospital labor } \\
\text { (hours) }\end{array}$} & \multirow{3}{*}{$\boldsymbol{p}$} \\
\hline & & & \multicolumn{2}{|c|}{ Up to 8} & \multicolumn{2}{|c|}{ More than 8} & \\
\hline & $\mathrm{n}$ & $\%$ & $\mathrm{n}$ & $\%$ & $\mathrm{n}$ & $\%$ & \\
\hline Oral diet offered & & & & & & & $<0,001^{*}$ \\
\hline Yes & 19 & 23.2 & 5 & 9.6 & 14 & 46.7 & \\
\hline No & 63 & 76.8 & 47 & 90.4 & 16 & 53.3 & \\
\hline Freedom of position and movement & & & & & & & $0.25^{\star *}$ \\
\hline Yes & 74 & 90.2 & 45 & 86.5 & 29 & 96.7 & \\
\hline No & 8 & 9.8 & 7 & 13.5 & 1 & 3.3 & \\
\hline $\begin{array}{l}\text { Non-pharmacological methods for pain } \\
\text { relief }\end{array}$ & & & & & & & $<0.01^{*}$ \\
\hline Yes & 53 & 64.6 & 25 & 48.1 & 28 & 93.3 & \\
\hline No & 29 & 35.4 & 27 & 51.9 & 2 & 6.7 & \\
\hline Presence of companion (prepartum) & & & & & & & $0.11^{*}$ \\
\hline Yes & 51 & 62.1 & 29 & 44.2 & 22 & 73.3 & \\
\hline No & 31 & 37.8 & 23 & 55.8 & 8 & 26.7 & \\
\hline Presence of companion (labor) & & & & & & & $0.10^{*}$ \\
\hline Yes & 34 & 41.5 & 18 & 34.6 & 16 & 53.3 & \\
\hline No & 48 & 58.5 & 34 & 65.4 & 14 & 46.7 & \\
\hline Use of partogram & & & & & & & $0.43^{*}$ \\
\hline Yes & 51 & 62.2 & 34 & 65.4 & 17 & 56.7 & \\
\hline No & 31 & 37.8 & 18 & 34.6 & 13 & 43.3 & \\
\hline
\end{tabular}

${ }^{*}$ Chi-square test ${ }^{* *}$ Fisher's Exact Test

Regarding frequencies of practices considered to be harmful or ineffective during labor and delivery and to be abandoned, it was observed that enema and trichotomy were not routinely used, occurring in only $3.7 \%$ of all puerperae. The lithotomy position was routinely used during delivery, being reported by $92.7 \%$ of postpartum women. The Kristeller maneuver was used in $20.7 \%$ of deliveries. In the comparison between the puerperae with hospital delivery time of up to eight and more than eight hours, none of these four practices presented significant difference (all p values were $>0.05$ ) (Table 3 ).

Table 3. Frequencies of practices clearly harmful or ineffective during labor and delivery for total postpartum women with up to 8 and more than 8 hours of hospital labor $(n=82)$.

\begin{tabular}{|c|c|c|c|c|c|c|c|}
\hline \multirow{3}{*}{ Variables } & \multirow{2}{*}{\multicolumn{2}{|c|}{ Total }} & \multicolumn{4}{|c|}{$\begin{array}{c}\text { Hospital labor time } \\
\text { (hours) }\end{array}$} & \multirow[t]{3}{*}{$\boldsymbol{p}$} \\
\hline & & & \multicolumn{2}{|c|}{ Up to 8} & \multicolumn{2}{|c|}{ More than 8} & \\
\hline & $n$ & $\%$ & $\mathrm{n}$ & $\%$ & $n$ & $\%$ & \\
\hline Enema & & & & & & & $1.00^{\star \star}$ \\
\hline Yes & 3 & 3.7 & 2 & 3.8 & 1 & 96.7 & \\
\hline No & 79 & 96.3 & 50 & 96.2 & 29 & 3.3 & \\
\hline Trichotomy & & & & & & & $0.55^{\star \star}$ \\
\hline Yes & 3 & 3.7 & 1 & 1.9 & 2 & 6.7 & \\
\hline No & 79 & 96.3 & 51 & 98.1 & 28 & 93.3 & \\
\hline Lithotomy position during delivery & & & & & & & $0.66^{\star \star}$ \\
\hline Yes & 76 & 92.7 & 49 & 94.2 & 27 & 90.0 & \\
\hline No & 6 & 7.3 & 3 & 5.8 & 3 & 10.0 & \\
\hline Kristeller maneuver & & & & & & & $0.12^{*}$ \\
\hline Yes & 17 & 20.7 & 8 & 15.4 & 9 & 30.0 & \\
\hline No & 65 & 79.3 & 44 & 84.6 & 21 & 70.0 & \\
\hline
\end{tabular}


The Table 4 shows frequency of practices that are frequently used inappropriately during labor and delivery, for all deliveries and with up to 8 and more than 8 hours of hospital labor.

Table 4. Frequency of practices that are frequently used inappropriately during labor and delivery, for all deliveries and with up to 8 and more than 8 hours of hospital labor $(n=82)$.

\begin{tabular}{|c|c|c|c|c|c|c|c|}
\hline \multirow{3}{*}{ Variables } & \multirow{2}{*}{\multicolumn{2}{|c|}{ Total }} & \multicolumn{5}{|c|}{ Admission time until delivery (hours) } \\
\hline & & & \multicolumn{2}{|c|}{ Up to 8} & \multicolumn{2}{|c|}{ More than 8} & \multirow[t]{2}{*}{$p$} \\
\hline & & $\%$ & $\mathrm{n}$ & $\%$ & $\mathrm{n}$ & $\%$ & \\
\hline Amniotomy & & & & & & & $1.00^{\star *}$ \\
\hline Yes & 4 & 4.9 & 3 & 5.8 & 1 & 3.3 & \\
\hline No & 78 & 95.1 & 49 & 94.2 & 29 & 96.7 & \\
\hline Oxytocin infusion & & & & & & & $0.01^{*}$ \\
\hline Yes & 34 & 41.5 & 16 & 30.8 & 18 & 60.0 & \\
\hline No & 48 & 58.5 & 36 & 69.2 & 12 & 40.0 & \\
\hline Analgesia & & & & & & & $0.37^{\star *}$ \\
\hline Yes & 1 & 1.2 & 0 & 0.0 & 1 & 3.3 & \\
\hline No & 81 & 98.8 & 52 & 100.0 & 29 & 96.7 & \\
\hline Episiotomy & & & & & & & $<0.01^{*}$ \\
\hline Yes & 30 & 36.6 & 12 & 23.1 & 18 & 60.0 & \\
\hline No & 52 & 63.4 & 40 & 76.9 & 12 & 40.0 & \\
\hline
\end{tabular}

Regarding the obstetric practices that are frequently used inappropriately during labor and delivery, amniotomy was performed in $4.9 \%$ of cases. Oxytocin infusion in the first or second periods of labor occurred in $41.5 \%$ of the analyzed births. In $1.2 \%$ of cases, analgesia was used and episiotomy was performed in $36.6 \%$ of women. There was a significant association for the puerperae with hospital delivery time of more than 8 hours and oxytocin infusion during the first and second periods of labor $(p=0.01)$ and episiotomy $(p<0.01)$, in relation to postpartum women with hospital delivery time of up to 8 hours (Table 4$)$.

\section{DISCUSSION}

This study evaluated the practices in hospital care during labor and normal delivery in a maternity hospital in Southern Brazil. Overall, the women surveyed may be considered young, with the vast majority having a partner and being white, many with less than eight years of schooling and most of them without paid work. The low age associated with low schooling favors unemployment and women's economic and social dependence [11].

Prenatal follow-up was performed by almost all the puerperae surveyed, similar to an evaluation that described obstetric care provided in two municipal public maternity hospitals during normal delivery in the city of Natal [12]. However, the authors reported that approximately half of the postpartum women had 7 or more prenatal consultations, a lower percentage than in this study.

As for the newborn characteristics, 3.7\% of pregnancies younger than 37 weeks at delivery, higher [12] and slightly lower [13] prematurity value than reported in the literature. Newborns weighting less than 2,500 grams at birth were close to those of other studies [12-13]. Apgar values of 8 or more in the fifth minute were considered satisfactory and better when compared to the literature [12].

In the evaluation of quality of care for labor and normal delivery, among the practices that are demonstrably useful and that should be encouraged is the offer of oral diet for the parturient. In this study, the supply of oral diet, including liquids and solids, was reported by almost a quarter of the puerperae surveyed. Similarly, women with usual obstetric risk received an oral diet in a survey that evaluated the use of good practices and obstetric interventions in labor and delivery care with data from the research Nascer no Brasil, conducted in 2011 and 2012 [14]. Studies have reported an oral diet offer during labor of 54.6\% [1] and zero diet in $62 \%$ of parturients [13]. In this study, the hospital labor time of more than 8 hours was significantly associated to the useful practices of offering oral diet. Restricting liquids and food during labor is a common practice in many healthcare facilities. Restriction of oral ingestion may be unpleasant for some women and may adversely influence their labor experience [15]. The low percentage of oral diet offerings may be linked to the uncertainties of possible interventions such as emergency cesarean section. However, the Ministry of Health recommends that women in labor may ingest liquids, preferably isotonic solutions and not just water. In addition, those who are on opioid or do not present imminent risk factors for general 
anesthesia may eat a light diet [10]. In fact, since the evidence does not show benefits or damages, there is no justification for restricting liquids and foods during labor for women at low risk of complications [15].

Freedom of position and movement were reported by the vast majority of postpartum women. This result was similar to a study that sought to evaluate delivery care in health institutions, where physicians and obstetrical nurses worked together in Belo Horizonte, where 230 and 238 postpartum women were surveyed for practices in labor and delivery, respectively. Of the 230 postpartum women surveyed during labor, $96 \%$ reported free movement [1]. The freedom of movement for the parturient has also been reported in other studies $[11,14,16]$, reinforcing the practice of vertical position during labor. The benefits of adequate parturient mobility positively influence labor by increasing pain tolerance, avoiding drug use, and improving the course of dilation and reducing the duration of the labor active phase, as evidenced in one clinical trial performed at the Centro de Obstetrícia do Hospital Universitário de São Paulo (USP), in which a comparative analysis was performed between a treatment group and a control group, both with 50 parturients each [17].

Another practice with a high percentage of reporting was the use of non-pharmacological methods for pain relief, by $62.6 \%$ of postpartum women, a value lower than that found in a previously cited study $(74.2 \%)$ [1], but at least twice as high than that reported in the literature [14]. The hospital labor time of more than 8 hours was significantly associated to the useful practices of non-pharmacological methods for pain relief. The increased use of non-pharmacological methods for pain relief may demonstrate the healthcare team concern to provide greater comfort to the parturient as labor time is prolonged. The majority of postpartum women in this study reported performing sprinkling in hot water and massage, practices that are recommended by the Ministry of Health [10]. At Centro de Parto Normal Casa de Maria, in the city of São Paulo, where 991 parturients and their newborns were surveyed between 2003 and 2006, sprinkler bath $(71.0 \%)$ or immersion $(21.9 \%)$ and comfort massage (29.8\%) [11] were also used. Sprinkler bath was reported in $23.48 \%$ of women, identifying practices used by obstetric nurses in delivery care in two public maternity hospitals in Rio de Janeiro, where 4,787 births were evaluated, of which 2,914 were monitored by obstetric nurses [16]. Importantly, the offer of non-pharmacological methods for pain relief demonstrates support by the team in taking measures to make labor more comfortable, supporting the parturient's choice.

In this study, the presence of companion was evaluated during the prepartum period and at delivery. A companion rate of around $60 \%$ in the prepartum period and $40 \%$ in the delivery was observed, data considered satisfactory when compared to the presence of family members during labor of $19.5 \%$ [13] and between 0.9 and $19.2 \%$ [18]. However, the values found could be even higher, as reported in the literature (95.4\% [11], 92.2\% [11] and 86.7\% [12]). In a Brazilian research [14], 24.5\% of women had no companion, $56.7 \%$ had partial companion and only $18.8 \%$ had continuous companion. The independent predictors of not having a companion or partial companion were the low income and schooling, brown skin, use of the public sector, multiparity and vaginal delivery [19]. It should be considered that the evaluation of this indicator can be hampered if there is a lack of structure of maternity hospitals in welcoming the companion and ensuring privacy to the other patients. In the maternity hospital studied, it was requested that, whenever possible, the companion of choice was female, seeking to maintain greater comfort and privacy for the parturients. The presence of family members in the delivery is a right guaranteed in Brazil by Law 11108/2005, regulated by the Ministry of Health by the Administrative Rule 2418/2005 [20]. The main benefits of continuous support in childbirth (not necessarily family/friends) would be the reduction of labor time [21-22], the lower propensity to use oxytocin [21] and analgesia, a better satisfaction and positive experience of childbirth, the lower incidence of cesarean section [10,21-22] and instrumentalized vaginal delivery [10]. This latter benefit is most evident when performed by non-professionals of the hospital, but partners, relatives, friends and doulas. Continued support at childbirth would require further investment in the training and placement of healthcare professionals. However, these investments could lead to lower costs, considering the benefits, such as the reduction of procedures and interventions [10].

The presence of a partograph in $62.2 \%$ of medical records is above the average reported in a survey conducted in Brazil (41.4\%) and $28.5 \%$, described in a study evaluating the quality of hospital care for normal delivery in Goiânia, with 404 women in 13 hospitals [13]. In a different way, 77.4\% of partogram was found in the monitoring of labor progression [1] and 93.4 and $99.11 \%$ during the evaluation of 213 and 222 patients, respectively, in two maternity hospitals in Rio de Janeiro, using WHO standards as standard [18]. The frequency of this non-existent or incompletely filled document reached almost $40 \%$ in this study and a very low value of its use [12], even though it is known from the evidence that its use can bring benefits. A WHO partograph template or equivalent, with a 4-hour course of action, should be used to record the labor progress [10]. 
With regard to clearly harmful or ineffective practices that should be eliminated from labor and delivery, enema and trichotomy were reported in only $3.7 \%$ for both cases, indicating their almost complete elimination during labor care in the maternity hospital in matter. This also occurred in a study conducted in Belo Horizonte, where no enema and trichotomy were performed [1], and in a study conducted in Goiânia, the enema was performed in a very low percentage [13]. However, values of $17 \%$ and $38.4 \%$ for enema and $63.3 \%$ and $41.1 \%$ for trichotomy practice in vaginal deliveries [18] and $41.1 \%$ of trichotomy [13] were still found. The National Guideline on Assistance to Normal Delivery, elaborated by the Ministry of Health, makes it clear that enema and pubic and perineal trichotomy should not be performed routinely during labor [10]. Despite this, the practice of trichotomy remains incorporated in the puerperae culture, and among those who did not undergo trichotomy in a hospital environment, $92.2 \%$ reported that this practice was performed at home.

The lithotomy position during delivery was reported by $92.7 \%$ of parturients. This high percentage may indicate a model of attention marked by harmful or ineffective interventions. Some studies have shown similar results, with percentages of $98.8 \%$ [18] and $97.1 \%$ [14] for lithotomy position and $100 \%$ for supine position [13]. The lying position for delivery is culturally rooted, not only by healthcare professionals, but also by the patients themselves [1]. However, some publications have shown greater proportions of the use of nonlithotomic positions in delivery [16,23-24], which may indicate a search for changes in practices related to the pregnant women care. In fact, the parturient should be discouraged from adopting the supine, horizontal or semi-supine dorsal decubitus positions during the second period of labor, but encouraged to adopt any other position she finds more comfortable, such as squatting, lateral or four supports [10]. A recent review suggests several possible benefits for upright position in women without epidural anesthesia, such as a slight reduction in the duration of the second stage of labor (especially in primigravidae) and reduction of episiotomy and assisted delivery rates [25].

Current recommendations suggest that the Kristeller maneuver should not be performed in the second period of labor [10]. In the present study, it was reported by approximately one fifth of postpartum women. Although the frequency was lower than $37.3 \%$ of women classified as usual obstetric risk [14] and other researches with even greater percentages [13-18], these rates were expected to be close to zero or very low, as in the evaluation carried out in Belo Horizonte, where only $9.3 \%$ reported this practice [1]. It seems that the phenomenon of using the Kristeller maneuver or compression of the uterine fund is more common than is disclosed, resulting in even legal implications against physicians and healthcare providers in the United States and the European Union [26].

Among the practices frequently used inappropriately during labor and delivery, amniotomy was described in $4.9 \%$ of charts, much smaller than those found in national studies, ranging from $40.7 \%$ a $82.2 \%[1,9,11,14]$. Early amniotomy, associated or not with oxytocin, should not be performed routinely in laboring women progressing well but may be considered in the suspicion of failure to progress in the first stage of labor with intact membranes. In these cases, amniotomy can decrease labor for approximately one hour and increase the intensity and pain of contractions [10].

The use of oxytocin should be considered when contractions are inadequate at the beginning of the second period of labor [10,27]. However, this practice was evidenced in $41.5 \%$ of cases in this study, and its use is even more frequent in other reports in the literature [1,12-13]. In this study, the longer hospital labor time (> 8 hours) was significantly associated with the often inadequately used practices of oxytocin infusion. Maybe the prolongation of hospital labor time is accompanied by anxiety feelings of the patient, her companion or the healthcare team. This could lead to interventionist practices in order to shorten labor time, practices that are sometimes unnecessary or inappropriate.

Oxytocin may cause, among other effects, increased intensity and frequency of uterine contractions, nausea, vomiting, stomach pain, cardiac arrhythmias and increased blood pressure. In this sense, it is important to monitor, during its administration, the frequency of uterine contractions, the patient's blood pressure and fetal heart rate [27].

The frequency of regional analgesia at delivery was extremely low. Other studies indicated very variable values, from the non-existence of analgesia to $54.4 \%[1,9,13-14,18]$. Although non-pharmacological methods for pain relief were used in the maternity hospital in matter, the frequency of regional analgesia was very low. The maternal request for labor analgesia comprises sufficient indication for its accomplishment, regardless of the stage of labor and the dilation degree, provided that it is clarified and discussed with the pregnant woman. However, the parturient should be alerted about association with negative outcome, adverse effects and major complications, as well as increased need for venous access and monitoring [10]. 
Currently, it is recommended that episiotomy should not be performed routinely during spontaneous vaginal delivery [10]. Considering this recommendation, the occurrence of episiotomy was observed in two public maternity hospitals in Rio de Janeiro in only $4.0 \%$ and $8.29 \%$ of cases [16], in $8.4 \%{ }^{1}$ of pregnant women surveyed in 11 maternity hospitals in Belo Horizonte and in $7.2 \%$ and $14.8 \%$ in other studies [9]. Thus, the value found in this study $(36,6 \%)$ can be considered higher than expected, as well as in other publications, ranging from $53.6 \%$ to $85.2 \%[11-14,18]$. Moreover, the longer hospital labor time showed a significant association with the often inadequately used practices of episiotomy. Many physicians believe that routine episiotomy prevents serious injury during labor. A recent review has shown that believing that routine episiotomy reduces perineal/vaginal trauma is not supported by the current evidence [28].

Among the limitations of the present study is the collection of information from medical records that depend on the quality of their completion. Nevertheless, many studies on the same subject use medical records as a source for data collection $[1,9,11,13-14,18]$. The information provided by the puerperal interviewees is subject to memory bias, which is minimized by the interview until 48 hours after delivery. Despite these limitations, the results may contribute to a better understanding of hospital care practices during labor and normal delivery.

It is expected that the results found may support strategies aimed at improving care during delivery. As examples, multidisciplinary model of hospital care, with integration of other health professionals; monitoring of labor and delivery with scientific rigor and humanization in care, with implementation of support actions and support to pregnant women in labor.

\section{CONCLUSION}

In the evaluation of the three categories of hospital care practices during labor and normal delivery, both percentages considered satisfactory and not satisfactory were observed. Hospital labor time longer than 8 hours was associated with offering oral diet, use of non-pharmacological methods for pain relief, oxytocin infusion and episiotomy.

It is important for the healthcare team to be able to accommodate women in labor at such an important time in their reproductive lives, providing adequate clinical and emotional support, and labor and delivery assistance with a minimum of intervention, compatible with the recommendations.

Funding: This research received no external funding.

Conflicts of Interest: The authors declare no conflict of interest.

\section{REFERENCES}

1. Souza AMM, Souza KV, Rezende EM, Martins EF, Campos D, Lansky S. Práticas na assistência ao parto em maternidades com inserção de enfermeiras obstétricas, em Belo Horizonte, Minas Gerais. Esc Anna Nery Rev Enferm. 2016;20(2):324-31.

2. Ministério da Saúde (BR). Cadernos HumanizaSUS 4ª ed. Brasília, DF: Ministério da Saúde; 2014. 244 p.

3. Victora CG, Aquino EML, Leal MC, Monteiro CA, Barros FC, Szwarcwald C. Saúde de mães e crianças no Brasil: progressos e desafios. Lancet. 2011;377(9780):1863-76.

4. Word Health Organization. Care in normal birth: a practical guide. Report of a Technical Working Group. Birth. 1997;24(2):121-3.

5. Ministério da Saúde (BR). Parto, aborto e puerpério: assistência humanizada a mulher. Brasília (DF): Ministério da Saúde; 2001. 202 p.

6. Bhutta ZA, Chopra M, Axelson H, Berman P, Boerma T, Bryce J et al. Countdown to 2015 decade report (200010): taking stock of maternal, newborn, and child survival. Lancet. 2010;375(9730):2032-44.

7. Andreucci CB, Cecatti JG. Desempenho de indicadores de processo do Programa de Humanização do Pré-natal e Nascimento no Brasil: uma revisão sistemática. Cad Saúde Pública. 2011;27(6):1053-64.

8. Hartz Z. Do monitoramento do desempenho ao desempenho do monitoramento: novas oportunidades para a avaliação na gestão da vigilância em saúde. Ciênc Saúde Coletiva. 2013;18(5):1201-16.

9. Vogt SE, Diniz SG, Tavares CM, Nagela CPS, Schnec CA, Zorzam B et al. Características da assistência ao trabalho de parto e parto em três modelos de atenção no SUS, no Município de Belo Horizonte, Minas Gerais, Brasil. Cad Saúde Pública. 2011;27(9):1789-800.

10. Ministério da Saúde (BR). Diretrizes nacionais de assistência ao parto normal: relatório de recomendação. Brasília: Ministério da Saúde, 2016. 381 p. 
11. Lobo SF, Oliveira SMJV, Schneck CA, Silva FMB, Bonadio IC, Riesco MLG. Resultados maternos e neonatais em Centro de Parto Normal peri-hospitalar na cidade de São Paulo, Brasil. Rev Esc Enferm. 2010;4(3):812-8.

12. Carvalho IS, Brito RS. Using the Bologna Score to acess normal delivery healthcare. Rev Esc Enferm USP. 2016;50(5):741-8.

13. Giglio MRP, França E, Lamounier LA. Avaliação da qualidade da assistência ao parto normal. Rev Bras Ginecol Obstet. 2011;33(10):297-304.

14. Leal MC, Pereira APE, Domingues RMSM, Theme Filha MM, Dias MAB, Nakamura-Pereira M et al. Intervenções obstétricas durante o trabalho de parto e parto em mulheres brasileiras de risco habitual. Cad Saúde Pública. 2014;30(1):17-32.

15. Ingata M, Tranmer J, Gyte GM. Restricting oral fluid and food intake during labour. Cochrane Database Syst Rev 2010; (1):CD003930.

16. Vargens OMD, Silva ACV, Progianti JM. Contribuição de enfermeiras obstétricas para consolidação do parto humanizado em maternidades no Rio de Janeiro-Brasil. Esc Anna Nery Rev Enf. 2017;21(1):e20170015.

17. Bio $E$, Bittar RE, Zugaib $M$. Influência da mobilidade materna na duração da fase ativa do trabalho de parto. Rev Bras Ginecol Obstet. 2006;28(11):671-9.

18. D'Orsi E, Chor D, Giffin K, Ângulo-Tuestac A, Barbosa GP, Gamae AS et al. Qualidade da atenção ao parto em maternidades do Rio de Janeiro. Rev Saúde Pública. 2005;39(4):646-54.

19. Diniz CSG, d'Orsi E, Domingues RMSM, Torres JA, Dias MAB, Schneck CA, et al. Implementação da presença de acompanhantes durante a internação para o parto: dados da pesquisa nacional Nascer no Brasil. Cad Saúde Pública. 2014;30(1):140-53.

20. Brasil. Lei n.11.108, de 7 de abril de 2005. Dispõe sobre o direito da parturiente à presença de acompanhante durante o trabalho de parto, parto e pós-parto imediato, no âmbito do SUS Brasília; 2005.

21. Brüggemann OM, Parpinelli MA, Osis MJD. Evidências sobre o suporte durante o trabalho de parto/parto: uma revisão da literatura. Cad Saúde Pública. 2005;21(5):1316-27.

22. Hodnett ED, Gates S, Hofmeyr GJ, Sakala C. Apoyo continuo para las mujeres durante el parto. La Biblioteca Cochrane Plus. 2011;(2):CD003766.

23. Mouta RJO, Pilotto DTS, Vargens OMC, Progianti JM. Relação entre posição adotada pela mulher no parto, integridade perineal e vitalidade do recém-nascido. Rev Enferm UERJ. 2008;16(4):472-6.

24. Rocha CR, Fonseca LC. Assistência do enfermeiro obstetra a mulher parturiente: em busca do respeito a natureza. Rev Pesq Cuidado é Fundam. 2010;2(2):807-16.

25. Gupta JK, Sood A, Hofmeyr GJ, Vogel JP. Position in the second stage of labour for women without epidural anaesthesia. Cochrane Database of Systematic Reviews 2017, Issue 5. Art. №: CD002006.

26. Malvasi A, Zaami S, Tinelli A, Trojano G, Montanari, Vergallo G et al. Kristeller maneuvers or fundal pressure and maternal/neonatal morbidity: obstetric and judicial literature review. J Matern Fetal Neonatal Med. 2018;21:1-10.

27. Osilla EV, Sharma S. Oxytocin. StatPearls [Internet]. Treasure Island (FL): StatPearls Publishing; 2018. [Accessed in: 2019 Sep. 12]. Available from: https://www.ncbi.nlm.nih.gov/books/NBK507848/

28. Jiang H, Qian X, Carroli G, Garner P. Selective versus routine use of episiotomy for vaginal birth. Cochrane Database Syst Rev. 2017;8(2):CD000081.

2020 by the authors. Submitted for possible open access publication under the terms and conditions of the Creative Commons Attribution (CC BY NC) license (https://creativecommons.org/licenses/by-nc/4.0/). 